\title{
Efficacy and Safety of Microwave Ablation (MWA) for Hepatocellular Carcinoma (HCC) in Difficult Anatomical Sites in Egyptian Patients with Liver Cirrhosis
}

\author{
Ahmad F Soliman', Mahmoud M Abouelkhair ${ }^{1}$, Maha S Hasab Allah ${ }^{1}$, Nabil \\ M El-Kady ${ }^{1}$, Wafaa M Ezzat ${ }^{2}$, Haitham A Gabr'2, Ehab H Elsayed ${ }^{2}$, Ahmed I \\ Saleh $^{2 *}$, Amira Kamel ${ }^{3}$
}

\begin{abstract}
Background and aim: Imaging guided microwave ablation (MWA) for hepatocellular carcinoma (HCC) has become a widely used method over recent years. Tumors close to the diaphragm, gastrointestinal tract, gallbladder, pancreas, hepatic hilum and major bile duct or vessels are generally considered relative contraindications for microwave ablation. This study was conducted to assess the effectiveness and safety of ultrasonography-guided MWA in treating patients with HCC in difficult anatomical sites in comparison to those in conventional sites. Patients and methods: Eighty-eight patients were included and divided into two groups: the study group of 44 with 46 lesions lying $<5 \mathrm{~mm}$ from the diaphragm, hepatic capsule, gall bladder (GB) or large vessel; and the control group of 44 patients with 50 lesions in non-risky sites. Each lesion was ablated using an ultrasound guided microwave probe using a detailed protocol. Results: Most of the patients were males, with a mean age of 57.8 years. In the study group, two patients had lesions adjacent to the GB, twelve were perivascular and 32 were subcapsular. The overall successful ablation rates were $84.8 \%$ and $92 \%$ in the study and control groups, respectively. Within the study group, ablation rates were $100 \%, 75 \%$ and $87.5 \%$ for lesions close to the GB, perivascular lesions and subcapsular lesions, respectively. One patient developed a subcutaneous abscess, with good outcome after proper treatment. Fever, pain and asymptomatic pleural effusion were reported after ablation without statistically significant difference between the groups or among subgroups. In conclusion: MWA for HCC in difficult anatomical sites is as effective and safe as for ordinary sites.
\end{abstract}

Keywords: Difficult sites- Hepatocellular Carcinoma (HCC)-Liver cirrhosis-Microwave Ablation (MWA)

Asian Pac J Cancer Prev, 20 (1), 295-301

\section{Introduction}

Hepatocellular carcinoma (HCC) accounts for nearly $90 \%$ of the primary liver tumors and is currently the third leading cause of cancer death worldwide (El-Serag, 2011). The different treatment options include surgical resection, transplantation, local ablation, chemoembolization, radioembolization and molecular targeted therapies; these treatments can be combined in various ways to achieve different goals. Selection criteria for these treatments have been recommended by the American Association for the Study of Liver Diseases (AASLD) (Bruix and Sherman, 2011).

Imaging-guided thermal ablation with use of different energy sources, such as radiofrequency (RF), microwave (MW), high intensity- focused ultrasound (HIFU), or laser has been used with different success rates. The benefits of thermal ablation include low morbidity, few complications and repeatability for recurrence (Ahmed et al., 2014).

Microwaves could offer more direct heating than other energies, making MW ablation (MWA) more potent in organs with high blood perfusion or near vascular heat sinks as compared with other thermo-ablative modalities, and the MWA zones are uniform in shape and size and remain unaffected by convective heat loss (Brace, 2010). These advantages made MWA a widely used method for treatment of hepatic tumors.

Percutaneous ablation for tumors adjacent to the diaphragm has not been well accepted in the past due to tumor location and RF ablation systems. Tumors located adjacent to the diaphragm always have a limited sonic window due to overlapped lung or ribs, and the tumors are difficult to approach. RF ablation systems show some unfavorable factors for percutaneous ablation; however, the results of $\mathrm{Li}$ et al. provide evidence that under strict temperature monitoring, MWA for tumors adjacent to 
the diaphragm can be performed safely (Li et al., 2012).

Regarding hepatic tumors adjacent to large vessels some researchers have already put RFA into practice of treating liver tumors adjacent to large vessels and the result was satisfying (Teratani et al., 2006). However, as another kind of thermal ablation techniques, MWA has several theoretical advantages over RFA and these advantages may make MWA treatment less affected by heat-sink (Wright et al., 2005). Although MWA has been widely used in liver cancer therapy, there are no authoritative clinical achievements but only some foundational reports on the effects of treating the tumors adjacent to large vessels (Nan et al., 2010). It is worth noting that Huang and his co-workers concluded that, with strict temperature monitoring, US-guided percutaneous MWA in treating hepatocellular carcinoma adjacent to large vessels is safe and effective (Huang et al., 2014).

Perforation of the gastrointestinal tract has been reported as a serious complication of thermal ablation, with an overall incidence of $0.1-0.3 \%$. Some authors have recommended against the use of percutaneous thermal ablation when treating liver tumors adjacent to the gastrointestinal tract ( Mulier etal.,2002), whereas others have mentioned that RFA is safe for such tumors (Choi et al.,2004), Thermal injury may be prevented by strict temperature monitoring of hepatic marginal tissue adjacent to the gastrointestinal tract as concluded by one study using MWA on 61 hepatic lesions in 59 patients located less than $5 \mathrm{~mm}$ from the gastrointestinal tract with no immediate nor periprocedural or delayed complications of bile ducts injury were found (Zhou et al., 2009).

\section{Aim of the work}

The aim of the study is to assess the effectiveness and safety of US-guided MWA in treating patients with HCC in risky anatomical sites; adjacent to large vessels, diaphragm, gall bladder or gastrointestinal tract, in comparison to those in non-risky sites(defined later).

\section{Materials and Methods}

\section{Patients and Methods \\ Patients}

This study was started on 113 patients in Endemic Medicine department, Kasr Al-Ainy hospital (81 patients) and in hepatology unit of Arab contractors medical center (32 patients) in the period from January 2014 to June 2016, for patients having hepatocellular carcinoma that was diagnosed either by radiological, serological or histopathological methods, but the number included in our results were 88 patients ( 57 patients Kasr Al-Ainy hospital and 31 patients in hepatology unit of Arab contractors medical center) and 25 patients were excluded as they dropped during their follow up period. The study was carried out in accordance with good clinical practice (GCP) and Helsinki Declaration in 1975 (Shephard, 1976).

After signing an informed consent, we included patients with hepatocellular carcinoma proved by ultrasound, alpha fetoprotein, contrast enhanced CT scan or histopathologically. All patients had liver cirrhosis with Child-Turcotte-Pugh (CTP) class A or B. Absence of extra hepatic metastases was determined by means of a thorough clinical assessment, chest radiography, abdominal US, abdominal $\mathrm{CT}$ and/or PET scan.

We excluded patients of CTP class (C), or those with single lesion $>5 \mathrm{~cm}$ or those with 3 lesions each $>3 \mathrm{~cm}$ or multiple hepatic focal lesions (more than 3 ). Also, patients with portal vein thrombosis, extrahepatic metastases, INR $>1.5$ or platelets count $<60,000$ cells / dl were excluded.

Our study was conducted then on two groups; each consists of 44 patients:

Group (A): 44 patients with hepatic focal lesions located less than $5 \mathrm{~mm}$ (shortest distance from the lesion margin) from diaphragm, gall-bladder, gastrointestinal tract and large vessels (large vessels were defined as the first or second branch of the portal vein, the base of hepatic veins, or the inferior vena cava of which diameters being $\geq 3 \mathrm{~mm}$ )

Group (B): 44 patients with hepatic focal lesions located in safe site (more than $5 \mathrm{~mm}$ from hepatic surface, large vessels, gall-bladder and gastrointestinal tract) were included as a control group.

\section{Methods}

The focal lesions were assessed before starting MWA by using ultrasonography regarding lesions size, number, site and relation to important structures.

\section{MWA machine}

We used AMICA-microwave generator (2450Mhz/140W), stock no.330-812, via Angela Vacchi 23/25-04011 Aprilia (LT), Italy. The used probes were AMICA-PROBE coagulative performance with available gauge: $16 \mathrm{G}$ and shaft length: $270 \mathrm{~mm}$.

\section{MWA procedure}

Localization of the site using ultrasound(U/S). All patients were placed in a supine or left-lateral position depending on the operation plan and tumor location. Marking the skin for the site of entrance. Local disinfection using iodine tincture was then followed by sedation using intravenous (IV) propofol. Then local anesthetic at site of entry was applied. Doppler was applied at the presumed site of entry to avoid large vessels in the path of the needle. Under U/S guidance the needle was inserted at the lower border of the lesion using free hand technique. Depending on the tumor size, a detailed protocol supplied by MWA machine provider (AMICA) including time and power of ablation, was worked out for each patient. During the therapy, we monitored the hyper echoic area of ablation using grayscalesonography to decide the endpoint of treatment. After ablation of the tumor, the antenna was slowly withdrawn $(1 \mathrm{~cm}$ by $1 \mathrm{~cm})$, and MW emission was continued at a power of 20 watts, until the antenna pulled to just under the skin entrance site. This method allowed needle track cauterization to prevent tumor seeding and to minimize bleeding after ablation.

Patients were then transferred to recovery room where they monitored vitally and for the occurrence of early post ablation complications (bleeding or severe pain). Patients with no complications were discharged after an average 
period of 12 hours.

Patients were then contacted on daily basis for the first three days and then on weekly basis for the first month after ablation to report any complications (fever, rigors, vomiting and/or respiratory distress). If any complication was reported, patients were asked to attend for further evaluation according to their complaint.

After the first month, a triphasic CT abdomen study was done for every patient to assess tumor viability along with AFP. For those with good ablation; CT and AFP were repeated on the 3rd and 6th months after ablation. Irregular peripheral enhancement in scattered, nodular, or eccentric pattern occurring at the original sites which were previously considered to be completely ablated during the follow-up period was diagnosed as an incomplete ablation. Post procedure pain was assessed according to the Numeric Rating Scale (NRS-11) (an 11-point scale for patient self-reporting of pain) (National Institutes of Health-Warren Great Magnuson Clinical Center,2003).

\section{Statistical analysis}

Statistical package for social science (SPSS Inc., version 20 for windows 7) was used for data management and analysis. Mean \pm standard deviation (SD) for parametric data and t-student test was used for comparison. Median and interquartile range (IQR) presented non-parametric data and Mann Whitney U test was used for comparison. Qualitative data were presented as frequencies and percentages and compared by Chisquare test, when appropriate. In all tests $p$ value was considered significant if $\mathrm{P}<0.05$.

\section{Results}

Demographic and baseline data

The mean age of the studied patients was $57.8 \pm 6.2$ years. Seventy-one $(81 \%)$ patients were males. There was no significant difference between the two groups with regards to the distribution of different baseline data (Table 1).

\section{Hepatic focal lesions count and distribution}

The number of HFLs in the study group was 46 lesions; while in the control group was 50 lesions. Lesions less than $3 \mathrm{~cm}$ in their largest diameter were $27 \mathrm{HFLs}$ (58.7\%) and 32 HFLs (64\%) in the study and control
Table 1. Baseline and Session Data between Both Groups

\begin{tabular}{|c|c|c|c|}
\hline Variable & $\begin{array}{c}\text { Study (A) } \\
\mathrm{N}=44 \text { patients }\end{array}$ & $\begin{array}{c}\text { Control (B) } \\
\mathrm{N}=44 \text { patients }\end{array}$ & $\begin{array}{c}\mathrm{P} \\
\text { value }\end{array}$ \\
\hline \multicolumn{4}{|l|}{ Gender NO (\%) } \\
\hline Males (71) & $34(77.3 \%)$ & $37(84.1 \%)$ & 0.418 \\
\hline Females (17) & $10(22.7 \%)$ & $7(15.9 \%)$ & \\
\hline $\begin{array}{l}\mathrm{DM} \\
\mathrm{NO}(\%)\end{array}$ & $9(19.6 \%)$ & $11(22 \%)$ & 0.77 \\
\hline Age Years mean \pm S.D & $57 \pm 7$ & $59 \pm 5.4$ & 0.255 \\
\hline $\begin{array}{l}\text { Platelets* }\left(\mathrm{x} 10^{6}\right) / \mathrm{mL}^{3} \\
\text { median(IQR) }\end{array}$ & $116.5(52.7)$ & $103(51.7)$ & 0.12 \\
\hline $\begin{array}{l}\mathrm{ALT}^{*}(\mathrm{ULN}=40) \\
\text { median }(\mathrm{IQR})\end{array}$ & $58.5(38.0)$ & $50.5(46.0)$ & 0.73 \\
\hline $\begin{array}{l}\mathrm{AST}^{*}(\mathrm{ULN}=40) \\
\text { median(IQR) }\end{array}$ & $66(47.2)$ & $67(39.5)$ & 0.45 \\
\hline $\begin{array}{l}\text { INR } \\
\text { mean } \pm \text { S.D }\end{array}$ & $1.2 \pm 0.16$ & $1.2 \pm 0.12$ & 0.563 \\
\hline $\begin{array}{l}\text { Bilirubin }(\mathrm{mg} / \mathrm{dL}) \\
\text { mean } \pm(\text { S.D })\end{array}$ & $1.5 \pm 0.6$ & $1.4 \pm 0.6$ & 0.33 \\
\hline $\begin{array}{l}\text { Albumin }(\mathrm{g} / \mathrm{dL}) \\
\text { mean } \pm(\text { S.D })\end{array}$ & $3.2 \pm 0.5$ & $3.3 \pm 0.5$ & 0.23 \\
\hline $\begin{array}{l}\text { AFP* }(n g / m L) \\
\text { median(IQR) }\end{array}$ & $61.2 \pm 146.8$ & $26 \pm 105.7$ & 0.61 \\
\hline $\begin{array}{l}\text { HFL diameter } \mathrm{cm} \\
\text { mean } \pm \text { (S.D) }\end{array}$ & $3.1 \pm 1.2$ & $2.9 \pm 1.1$ & 0.396 \\
\hline $\begin{array}{l}\mathrm{HFL}<3 \mathrm{~cm} \\
\mathrm{NO}(\%) \mathrm{p}\end{array}$ & $24(52.1 \%)$ & $32(64 \%)$ & 0.59 \\
\hline $\begin{array}{l}\mathrm{HFL} \geq 3 \mathrm{~cm} \\
\mathrm{NO}(\%) \mathrm{p}\end{array}$ & $22(47.8 \%)$ & $18(36 \%)$ & \\
\hline $\begin{array}{l}\text { Power(watt) } \\
\text { mean } \pm \text { (S.D) }\end{array}$ & $57.8 \pm 18.2$ & $55.2 \pm 17.6$ & 0.75 \\
\hline $\begin{array}{l}\text { Time* (minutes) } \\
\text { median(IQR) }\end{array}$ & $4(4)$ & $4(4.2)$ & 0.85 \\
\hline
\end{tabular}

$\mathrm{P}<0.05$. is significan; $\mathrm{P}>0.05$. is non-significant; * (data represented in median and IQR); $\mathfrak{p}$, (Total Number of HFLs is $46 \& 50$ in study and control group respectively); HFLs (Hepatic focal lesions), AFP (alpha feto protein), INR (international normalized ratio) and DM (diabetes meliteus).

groups respectively, with no significant difference between both groups (Table 1).

HFLs distribution in segments VI, VII and VIII was found to be (31/46)67.4\% versus $(33 / 50) 66 \%$ in the study

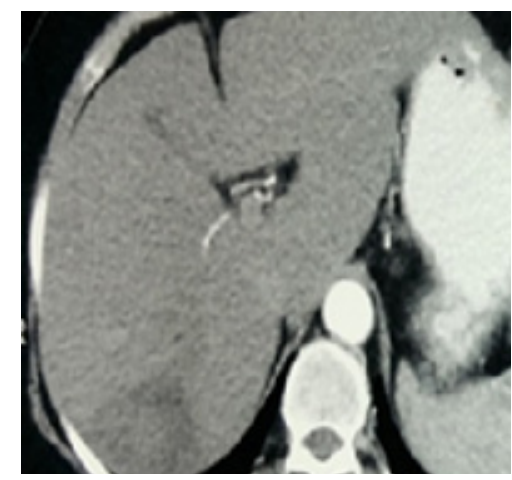

Figure 1. a. Triphasic CT abdomen (arterial phase) revealing subcapsular HFL before MWA. b. Same lesion (arterial phase) one month after MWA. 


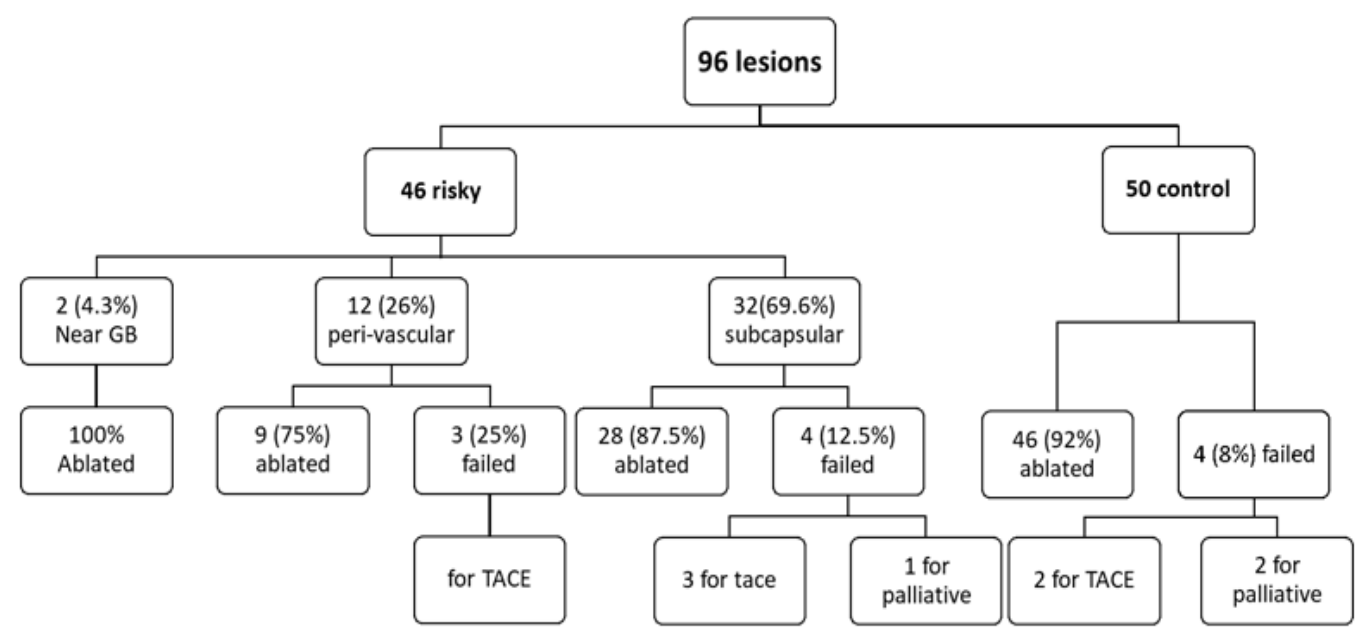

Figure 2. Summary of Study Outcome

group and control group respectively, which were more than their distribution in other liver segments.

Within the study group, (32/46) (69.6\%) of the lesions were subcapsular, while (12/46)26\% were close to vessels and only two lesions $(4.3 \%)$ were close to the gall bladder.

A mean power of 57.8 and 55.2 watts were used with a time [median(IQR)] of 4(4) and 4(4.2) minutes spent, for ablation sessions in the study group and the control group, respectively (Table 1).

Table 2. MWA Outcome, Relation to Baseline Data (in Both Groups), Tumor Size and MWA Power

\begin{tabular}{|c|c|c|c|}
\hline Variable & $\begin{array}{l}\text { Ablated } \\
\text { HFLs (85) }\end{array}$ & $\begin{array}{c}\text { Failed } \\
\text { HFLs (11) }\end{array}$ & $\begin{array}{c}\mathrm{P} \\
\text { value }\end{array}$ \\
\hline \multicolumn{4}{|l|}{ Gender } \\
\hline Male $(\mathrm{N}=78)$ & $69(88.5 \%)$ & $9(11.5 \%)$ & 0.96 \\
\hline Female $(n=18)$ & $16(88.9 \%)$ & $2(11.1 \%)$ & \\
\hline $\begin{array}{l}\text { Age (years) } \\
\text { mean } \pm \text { (S.D) }\end{array}$ & $58 \pm 6.2$ & $56.4 \pm 6.7$ & 0.431 \\
\hline $\begin{array}{l}\text { ALT* }^{*}(\mathrm{U} / \mathrm{ml}) \\
\text { Median (IQR) }\end{array}$ & $54(38)$ & $50(49)$ & 0.84 \\
\hline $\begin{array}{l}\mathrm{AST}^{*}(\mathrm{U} / \mathrm{ml}) \\
\text { Median (IQR) }\end{array}$ & $67(45.5)$ & $66(60)$ & 0.87 \\
\hline $\begin{array}{l}\text { INR } \\
\text { mean } \pm(\text { S.D })\end{array}$ & $1.2 \pm 0.1$ & $1.2 \pm 0.1$ & 0.798 \\
\hline $\begin{array}{l}\text { Bilirubin }(\mathrm{mg} / \mathrm{dl}) \\
\text { mean } \pm(\text { S.D })\end{array}$ & $1.4 \pm 0.6$ & $1.7 \pm 0.4$ & 0.054 \\
\hline $\begin{array}{l}\text { Albumin }(\mathrm{g} / \mathrm{dl}) \\
\text { mean } \pm(\text { S.D })\end{array}$ & $3.3 \pm 0.4$ & $3.2 \pm 0.58$ & 0.642 \\
\hline $\begin{array}{l}\text { HFL biggest } \\
\text { Diameter }(\mathrm{cm}) \\
\text { mean } \pm(\text { S.D })\end{array}$ & $2.9 \pm 1.1$ & $3.4 \pm 1.3$ & 0.168 \\
\hline $\begin{array}{l}\text { Power (watt) } \\
\text { mean } \pm \text { (S.D) }\end{array}$ & $55.4 \pm 17.4$ & $64.5 \pm 20.1$ & 0.112 \\
\hline
\end{tabular}

Table 3. Comparison between Both Groups Regarding Post MWA Complications

\begin{tabular}{lccc}
\hline Complications & $\begin{array}{c}\text { Study (A) } \\
\text { N=44 patients }\end{array}$ & $\begin{array}{c}\text { Control (B) } \\
\text { N=44 patients }\end{array}$ & $\begin{array}{c}\mathrm{P} \\
\text { value }\end{array}$ \\
\hline Abscess & $1(2.3 \%)$ & $0(0 \%)$ & 0.315 \\
NO (\%) & & & \\
Pleural effusion & $3(6.8 \%)$ & $0(0 \%)$ & 0.78 \\
NO (\%) & & \\
Pain grade 1 & $28(63.6 \%)$ & $27(61.3 \%)$ & 1 \\
NO (\%) & & \\
$\begin{array}{l}\text { Pain grade 2-3 } \\
\text { NO (\%) }\end{array}$ & $16(36.3 \%)$ & $17(38.6 \%)$ \\
Low grade Fever & $14(31.8 \%)$ & $15(34 \%)$ & 0.813 \\
NO (\%) & & \\
\hline P $<0.05$ is significant; $>0.05$ is non-significant.
\end{tabular}

\section{MWA outcome in both groups}

After MWA was done, 39 (84.7\%) lesions were successfully ablated in the study group compared to $46(92 \%)$ lesions in the control group as was proven by triphasic CT study done one month after ablation. However, this was statistically non-significant $(\mathrm{P}$ value $=0.27)$.

Cases in whom MWA was unsuccessful in the study group were 4 subcapsular and 3 perivascular HFLs, where these tumors failed to achieve complete ablation, and they were referred for trans-arterial chemo-embolization (TACE). In one patient with subcapsular lesion tumor

Table 4. Pain Grades (According to the Numeric Rating Scale) (Kang et al.,2014) in Relation to the Site of HFLs (in Both Groups)

\begin{tabular}{lccc}
\hline Variable & \multicolumn{2}{c}{ Pain } & P value \\
& G1 N=63 & G2-3 N=33 & \\
\hline HFL size & $2.3 \pm 0.6$ & $4.1 \pm 0.9$ & $<0.010$ \\
Mean \pm S.D & & & \\
Power & $51.5 \pm 17.2$ & $65.7 \pm 15.4$ & $<0.010$ \\
Mean \pm S.D & & & \\
\hline
\end{tabular}

$\mathrm{P}<0.05$ is significant; $\mathrm{P}>0.05$ is non-significant 
spread occurred in the form of multiple HFLs for which the patient was kept for palliative treatment.

Four HFLs in the control group failed to achieve complete ablation; two HFLs were referred for TACE after receiving two sessions of MWA for each, while the other two lesions, were kept for conservative management due to the appearance of multiple hepatic focal lesions (Figure 1,2).

\section{MWA outcome in relation to other variables}

MWA outcome was not found to be related to the baseline data of patients (age, gender, CHILD score, bilirubin, albumin, ALT, AST, INR, HFLs size and power) (Table 2) in both groups.

Each subgroup alone in the study group, as same as control group, showed also no relation between the MWA outcome and tumor size (sub-capsular HFLs group $\mathrm{p}=0.441$,perivascular HFLs group $\mathrm{p}=0.098$ and control HFLs group $\mathrm{p}=0.077$ ), also no relation was found between MWA outcome and power used to ablate in different

Subgroups (sub-capsular HFLs group $\mathrm{p}=0.321$, perivascular HFLs group $\mathrm{p}=1.000$ and control HFLs group $\mathrm{p}=0.161$ ).

\section{Post MWA complications and follow up period}

Three months post MWA, Study and control groups showed a significant decrease in AFP level [median(IQR) 22.9 (52.3) vs 17.2(30) respectively, $\mathrm{P}<0.010$ in both groups] also 6 months post MWA AFP level significantly decreased in study and control groups [median(IQR) $19.1(28.3)$ vs $19.9(27.2)$ respectively, $\mathrm{P}<0.010$ in both groups].

Post MWA, no major complications were reported either early or late except for one diabetic patient who developed percutaneous abscess which required drainage and IV antibiotics with subsequent complete resolution later.

Indeed, minor complications were reported in the form of pain, fever and mild pleural effusion with no statistically significant difference between the two groups (Table 3), Mild pain severity was noted 4-6 hours post-procedure decreasing all over the next 24 hours, ranging from grade 1- to 3; according to Numeric Rating Scale of pain.

Low grade fever was documented in both groups; in view of the occurrence of post ablation syndrome in the literature all patients were prescribed acetaminophen (table 3). Three patients with sub capsular HFLs (6.8\%) were found to have mild right pleural effusion post procedure, which required only conservative management.

The occurrence of minor complications had no relationship neither with the outcome of MWA, nor with the site of HFLs in both groups, however pain grades was found to be directly proportionated with size of HFLs and the power used to ablate it (table 4).

\section{Discussion}

Malignant hepatic lesions in difficult sites; for locoregional ablation, are those in close proximity $(\leq 5 \mathrm{~mm})$ to bowel, hepatic capsule or major blood vessel. Thermal ablation of these lesions confers a challenge as it is usually associated with more complications and more local tumor progression rates. Using MWA for $\mathrm{HCC}$ has evolved very much during the past decade and proved to be as effective and safe as RFA (Luo et al., 2017). There are insufficient data to support the use of MWA for hepatic lesions in difficult sites.

In one study (Li et al., 2012), a total of 91 out of 96 subcapsular tumors $(94.8 \%)$ were ablated with local tumor progression 18.8\% (18/96) during follow-up after MWA, while there were no major complications reported and few minor complications were easily controlled in the form of pain and pleural effusion. Another study used MWA for lesions adjacent to the gall bladder achieved similar results of complete ablation with absence of major complications too (Li et al.,2015). Moreover, Huang and his colleagues used MWA for 163 perivascular lesions with initially ablation success of 157 lesions (96.3\%) and local tumor progression was detected in 22 of 163 tumors $(13.5 \%)$ (Huang et al.,2014).

In our study, regarding effectiveness, MWA for HCC in difficult sites was as effective as it was in the control group, with overall ablation rate of $84.8 \%$ for the study group versus $92 \%$ in the control group without statistically significant difference. However, for the subgroup of lesions adjacent to the gall bladder, the number was too small to be of significance. In the subcapsular lesions subgroup, 28 out of 32 lesions ( $87.5 \%$ ) were successfully ablated without local recurrence, using a total mean power of 55.3 watt, while, nine out of 12 perivascular lesions (75\%) were successfully ablated.

Lesion size did not seem to affect the efficacy of ablation in study subgroups and in the control group, as lesions less than $3 \mathrm{~cm}$ in diameter showed similar results to those $\geq 3 \mathrm{~cm}$ in diameter. This can be explained by the tailored session protocol according to the tumor size.

Our results were comparable to the studies utilizing RFA in treating subcapsular lesions, where we achieved $87.5 \%$ with no local recurrence, while other studies had similar results to our study with ablation success rates of 89.4 to $93 \%$ with variable rates of local recurrence (Kim et al., 2008; Filippousis et al., 2011; Kang et al., 2016).

Despite the low incidence of perivascularHCC during the study period and the difficulty to compare this low sample by other studies, but after stratification of perivascular HCC according to size, $5(71.4 \%)$ out of 7 HFLs $(\geq 3 \mathrm{~cm})$ and $4(80 \%)$ out of 5HFLs $(<3 \mathrm{~cm})$ were ablated with no local recurrence. In other studies where RFA was used for perivascular HCC, success rate was $52 \%(16 / 31 \mathrm{HFLs})$ after a median follow up period of about 11 months (Mulier et al., 2002),92\% (48 out of 52 small HFLs) with $11 \%$ local recurrence ( $\mathrm{Ng}$ et al., 2006), $100 \%$ (58 out of 58 small HFLs) with local recurrence of $20.8 \%$ during median follow up period of 17 months (Kang et al.,2014).

Regarding post procedure complications, minor complications were defined as those side effects which require :

- No therapy, no consequence or

- Nominal therapy, no consequence; includes overnight admission for observation only.

While major complications are those which:

Asian Pacific Journal of Cancer Prevention, Vol 20 
- Require therapy, minor hospitalization ( $<48$ hours) or

- Require major therapy, unplanned increase in level of care, prolonged hospitalization ( $>48$ hours) or

- Cause permanent adverse sequelae or

- Death.

In the present study there were no major complications except for one patient who developed subcutaneous abscess, which occurred after an ablation session for subcapsular HFL. No major complications were noticed in control group.

This low incidence of major complications also was reported in studies using MWA for HFLs located in safe sites, where intra-peritoneal hemorrhage, portal vein thrombosis, bile duct injury, obstructive jaundice,hemothorax, pneumothorax, symptomatic pleural effusion, gastrointestinal perforation, liver abscess, skin burn and tumor seeding were reported with incidence ranging from $0.18 \%$ to $3.67 \%$ (Kuang et al., 2007; Martin et al., 2007; Zhang et al., 2008).

Moreover, using MWA in risky sites, major complications reported were also low, as $1.9 \%$ (tumor seeding 1/53 HFLs near GIT) (Zhou et al., 2009), 3.1\% (moderate to massive pleural effusion 3/96 sub capsular HFLs) (Li et al., 2012), one case of portal vein thrombosis $(0.7 \%)$ and two cases of tumor seeding $(1.4 \%)$ out of 139 perivascular HFLs in the study done by Huang and his colleagues (Huang et al., 2014).

We used a mean power of 57.4 watts in ablation sessions for our patients, this may explain the low incidence of complications as was suggested by some authors who concluded that using an ablation power between $50-60$ watt during the procedure is a sufficient power for good ablation without causing major complications (Nan et al., 2010; Kang et al., 2016). In addition to the power used, safety may be associated also with the frequency of the microwave machine. Currently, two kinds of frequencies: 915 and 2,450 MHz are used for MWA. In this study we used AMICA-microwave generator $(2,450 \mathrm{Mhz})$. A frequency of $2,450 \mathrm{MHz}$ is more commonly adopted, which is also the frequency used in conventional microwave ovens given optimal heating profiles (Tanaka and Sato, 2007). Microwaves of $915 \mathrm{MHz}$ can penetrate more deeply than 2,450 MHz microwaves (Sun et al., 2012), therefore, the low frequency MWA may theoretically yield larger ablation zones (El-Serag, 2011), with possible higher rate of complications.

Peri-procedural pain and fever are considered symptoms of post-ablation syndrome, which may be the result of an inflammatory response to the necrotic tissue with cytokines production (Carrafiello et al., 2007).

Patients of both groups experienced mild degrees of fever and or pain of similar percentages of occurrence and no significant difference, while none of our patients reported severe pain or pain that impaired their daily routine. Moreover, pain grade was proportionate to the size of the lesion being ablated and to the power used in the session, however, it did not show any significant correlation with the tumor site. This agrees with the fact that the greatest predictor of development post-ablation syndrome is the volume of the ablated tumor (Foltz, 2014), where patients undergone ablation of hepatic tumor $<3.25$ $\mathrm{cm}$ are unlikely to develop post-ablation syndrome (Dodd et al., 2005).Moreover, in the current study, paracetamol $(1,000 \mathrm{mg})$ was prescribed on routine basis for patients post-MWA, and this may have had a role reducing the incidence of pain and fever.

Asymptomatic pleural effusion occurred in 3 cases with subcapsular lesions out of 44 patients $(6.8 \%)$, while none of the other subgroups or control group developed pleural effusion. The occurrence of post thermal ablation pleural effusion was said to be due to transient pleurisy related to thermal effect. The direct thermal damage of pleural membranes might cause increased pleural capillary filtration and interferes with parietal pleural fluid removal leading to pleural effusion formation (Chao et al., 2015).

In conclusion; MWA in difficult sites is as effective and safe as in ordinary sites. Further studies are required, especially for lesions close to gut. We encourage the use of MWA in difficult sites with precautions as mentioned in the study methodology.

Study limitations: We did not perform contrast enhanced ultrasound (CEUS) after sessions as it is unavailable at any of the two facilities, this might have affected the outcome as some studies used it to verify ablation and to monitor the need for complementary MWA session. The relatively short follow up period was also one of the limitations, however, in many cases one year follow up was reported, but data was insufficient to be analyzed and added to the current study results.

\section{Conflict of Interests}

The authors declare no conflicts of interest

\section{References}

Ahmed M, Solbiati L, Brace CL, et al (2014). Image-guided tumor ablation: standardization of terminology and reporting criteria--a 10-year update. Radiology, 273, 241-60.

Brace CL (2010). Microwave tissue ablation: biophysics, technology, and applications. Crit Rev Biomed Eng, 38, 65-78.

Bruix J, Sherman M (2011). Management of hepatocellular carcinoma: an update. Hepatology, 53, 1020-2.

Carrafiello G, Lagana D, Ianniello A, et al (2007). Post-radiofrequency ablation syndrome after percutaneous radiofrequency of abdominal tumours: one centre experience and review of published works. Australas Radiol, 51, 550-4.

Chao W-C, Liu C-Y, Lin C-C, et al (2015). Pleural effusion after percutaneous radiofrequency Ablation for hepatic malignancies. J Cancer Res Pract, 2, 22-30.

Choi D, Lim HK, Kim MJ, et al (2004). Therapeutic efficacy and safety of percutaneous radiofrequency ablation of hepatocellular carcinoma abutting the gastrointestinal tract. AJR Am J Roentgenol, 183, 1417-24.

Dodd GD, Napier D, Schoolfield JD, Hubbard L (2005). Percutaneous radiofrequency ablation of hepatic tumors: postablation syndrome. AJR Am J Roentgenol, 185, 51-7.

El-Serag HB (2011). Hepatocellular carcinoma. $N$ Engl J Med, 365, 1118-27.

Filippousis P, Sotiropoulou E, Manataki A, Konstantinopoulos O, Thanos L (2011). Radiofrequency ablation of subcapsular hepatocellular carcinoma. Eur J Radiol, 77, 299-304.

Foltz G (2014). Image-guided percutaneous ablation of hepatic malignancies. Semin Intervent Radiol, 31, 180-6. 
Huang S, Yu J, Liang P, et al (2014). Percutaneous microwave ablation for hepatocellular carcinoma adjacent to large vessels: a long-term follow-up. Eur J Radiol, 83, 552-8.

Kang TW, Lim HK, Lee MW, et al (2014). Perivascular versus nonperivascular small HCC treated with percutaneous RF ablation: retrospective comparison of long-term therapeutic outcomes. Radiology, 270, 888-99.

Kang TW, Lim HK, Lee MW, et al (2016). Long-term therapeutic outcomes of radiofrequency ablation for subcapsular versus nonsubcapsular hepatocellular carcinoma: A propensity score matched study. Radiology, 280, 300-12.

Kim YJ, Raman SS, Yu NC, (2008). Radiofrequency ablation of hepatocellular carcinoma: can subcapsular tumors be safely ablated?. AJR Am J Roentgenol, 190, 1029-34.

Kuang M, Lu MD, Xie XY, et al (2007). Liver cancer: increased microwave delivery to ablation zone with cooled-shaft antenna--experimental and clinical studies. Radiology, 242, 914-24.

Li M, Yu X, Liang P, Dong B, Liu F (2015). Ultrasound-guided percutaneous microwave ablation for hepatic malignancy adjacent to the gallbladder. Int J Hyperthermia, 31, 579-87.

Li M, Yu XL, Liang P, et al (2012). Percutaneous microwave ablation for liver cancer adjacent to the diaphragm. Int $J$ Hyperthermia, 28, 218-26.

Luo W, Zhang Y, He G, et al (2017). Effects of radiofrequency ablation versus other ablating techniques on hepatocellular carcinomas: a systematic review and meta-analysis. World $J$ Surg Oncol, 15, 126.

Martin RC, Scoggins CR, McMasters KM (2010). Safety and efficacy of microwave ablation of hepatic tumors: a prospective review of a 5-year experience. Ann Surg Oncol, 17, 171-8.

Mulier S, Mulier P, Ni Y, et al (2002). Complications of radiofrequency coagulation of liver tumours. $\mathrm{Br} J \mathrm{Surg}$, 89, 1206-22.

Nan Q, Lu Y, Liu Y, Zeng Y, (2010). Large blood vessel effect on thermal ablation with a water-cooled microwave antenna. 2010 3rd International Conference on Biomedical Engineering and Informatics, pp 16-8.

National Institutes of Health-Warren Great Magnuson Clinical Center "Pain Intensity Instruments". July 2003. Archived from the original (PDF) on 2012-09-14.

$\mathrm{Ng}$ KK, Poon RT, Lam CM, et al (2006). Efficacy and safety of radiofrequency ablation for perivascular hepatocellular carcinoma without hepatic inflow occlusion. Br J Surg, 93, 440-7.

Shephard DA (1976). The 1975 Declaration of Helsinki and consent. Can Med Assoc J, 115, 1191-2.

Sun Y, Cheng Z, Dong L, et al (2012). Comparison of temperature curve and ablation zone between 915- and 2450-MHz cooled-shaft microwave antenna: results in ex vivo porcine livers. Eur J Radiol, 81, 553-7.

Tanaka M, Sato M (2007). Microwave heating of water, ice, and saline solution: molecular dynamics study. J Chem Phys, 126, 034509.

Teratani T, Yoshida H, Shiina S, et al (2006). Radiofrequency ablation for hepatocellular carcinoma in so-called high-risk locations. Hepatology, 43, 1101-8.

Wright AS, Sampson LA, Warner TF, Mahvi DM, Lee FT Jr (2005). Radiofrequency versus microwave ablation in a hepatic porcine model. Radiology, 236, 132-9.

Zhang X, Chen B, Hu S, et al (2008). Microwave ablation with cooled-tip electrode for liver cancer: an analysis of 160 cases. Hepatogastroenterology, 55, 2184-7.

Zhou P, Liang P, Yu X, Wang Y, Dong B (2009). Percutaneous microwave ablation of liver cancer adjacent to the gastrointestinal tract. J Gastrointest Surg, 13, 318-24.

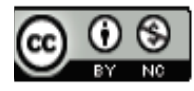

This work is licensed under a Creative Commons AttributionNon Commercial 4.0 International License. 